\title{
Diversity and cis-element architecture of the promoter regions of cellulose synthase genes in Eucalyptus
}

\author{
Nicky M Creux*, Minique H De Castro*, Martin Ranik, Mathabatha F Maleka, \\ Alexander A Myburg ${ }^{\S}$
}

Department of Genetics, Forestry and Agricultural Biotechnology Institute (FABI), University of Pretoria, Private Bag X20, Pretoria, 0028, South Africa

*These authors contributed equally to this work

${ }^{\S}$ Corresponding author

Prof A.A. Myburg

Department of Genetics

University of Pretoria

Tel: +27 (0)12-4204945

Fax: +27 (0)12-3625327

Email: zander.myburg@fabi.up.ac.za

Email addresses:

NMC: nicky.creux@fabi.up.ac.za

MHDC: decastrom@arc.agric.za

MR: martin.ranik@gmail.com

MFM: malekamf@ufs.ac.za

AAM: zander.myburg@fabi.up.ac.za

\begin{abstract}
Lignocellulosic biomass from fast-growing plantation trees is composed of carbohydrate-rich materials deposited into plant cell walls in a coordinated manner during wood formation. The diversity and evolution of the transcriptional networks regulating this process have not been studied extensively. We investigated patterns of species-level nucleotide diversity in the
\end{abstract}


promoters of cellulose synthase (CesA) genes from different Eucalyptus tree species and assessed the possible roles of DNA sequence polymorphism in the gain or loss of ciselements harboured within the promoters. Promoter regions of three primary and three secondary cell wall-associated CesA genes were isolated from 13 Eucalyptus species and were analysed for nucleotide and cis-element diversity. Species-level nucleotide diversity $(\pi)$ ranged from 0.014 to 0.068 and different CesA promoters exhibited distinct patterns of sequence conservation. A set of 22 putative cis-elements were mapped to the CesA promoters using in silico methods. Forty two percent of the mapped cis-element occurrences contained singleton polymorphisms which resulted in either the gain or loss of a cis-element in a particular Eucalyptus species. The promoters of Eucalyptus CesA genes contained regions that are highly conserved at the species (Eucalyptus) and genus (with Arabidopsis and Populus) level, suggesting the presence of regulatory modules imposing functional constraint on such regions. Nucleotide polymorphisms in the CesA promoters more frequently created new cis-element occurrences than disrupted existing cis-element occurrences, a process which may be important for the maintenance and evolution of cellulose gene regulation in plants.

Keywords: Cis-element conservation, promoter evolution, secondary cell wall, wood formation, CesA, woody biomass

\section{Introduction}

With the current worldwide focus on renewable energy production and carbon sequestration (Ragauskas et al. 2006; Piao et al. 2009), lignocellulosic biomass from fast-growing plantation trees is being targeted as a renewable source of carbon for biofuels and biomaterials (Regalbuto 2009; Rathmann et al. 2010). The bulk of this biomass is comprised 
of cellulose, hemi-cellulose and lignin contained in the secondary cell walls of wood fibre cells (Gorshkova et al. 2012). The biochemical and structural complexity of wood is determined largely by the coordinated expression of hundreds of regulatory, structural and biosynthetic genes (Aspeborg et al. 2005; Mellerowicz and Sundberg 2008). Several transcription factor genes have already been identified as key regulatory components of these pathways in the model plant Arabidopsis (Zhong et al. 2008; Zhong et al. 2010) and in woody plants such as Populus and Eucalyptus (Hu et al. 2010; Legay et al. 2010; McCarthy et al. 2010). Despite the emerging understanding of the molecular machinery underlying major biosynthetic pathways in wood-forming tissues, the nature and evolution of transcriptional networks regulating these pathways are not well described in woody plants such as Eucalyptus.

Eucalyptus is a richly diverse genus (Brooker 2000), containing over 700 species of woody plants, many of which are rapid and prolific producers of cellulose-rich biomass. Some of these species and their fast-growing hybrids form the basis of the most widely cultivated hardwood plantation crop in the world (Eldridge et al. 1994; Grattapaglia et al. 2009). The genus is divided into several subgenera (Pryor and Johnson 1971; Steane et al. 1999; Brooker 2000), of which the subgenus Symphyomyrtus is the largest and most diverse containing most of the commercially grown eucalypt species (Eldridge et al. 1994). The high phenotypic diversity in the subgenus is reflected at the DNA sequence level with nucleotide diversity values ranging from moderately diverse $(\pi=0.0186)$ for E. grandis (Novaes et al. 2008 ) to highly diverse $(\pi=0.063$ ) for E. loxophleba (with single nucleotide polymorphisms every 16 to 33 positions, Kulheim et al. 2009). These values are similar to the levels of nucleotide diversity reported in other outbred forest tree genera such as Pinus $(\pi=0.01-0.02)$ and Populus ( $\pi=0.005-0.01)$ (Reviewed in Neale and Ingvarsson 2008). The high nucleotide diversity in Eucalyptus and the recently completed E. grandis reference genome sequence 
(DOE JGI, http://www.phytozome.net) provide opportunities to investigate the evolution and diversity of regulatory networks underlying wood development.

In eukaryotes, gene regulatory networks comprise cis-acting sequence elements in promoters, trans-acting elements or transcription factors which bind to promoter sequences and the genes regulated by both kinds of factors. Cis-elements are often found clustered together in promoter regions where transcription factors can bind as hetero- or homodimers to modulate the transcription of the gene (Reviewed in Farnham 2009). Cis-regulatory elements are often shared by the promoters of co-expressed genes due to common trans-regulation (Vandepoele et al. 2009). Another feature of cis-element sequences is their conservation in orthologous promoters from different species and genera, in comparison to flanking noncoding sequences (Freeling and Subramaniam 2009). These unique features of cis-regulatory elements are employed in a host of computational algorithms for the in silico detection of ciselements (Tompa et al. 2005; Das and Dai 2007; Wijaya et al. 2008; Kim et al. 2009). Software programs, such as FootPrinter (Blanchette and Tompa 2003; Fang and Blanchette 2006), PHYLONET (Than et al. 2008) and PhyloScan (Carmack et al. 2007) are based on phylogenetic footprinting algorithms, which use the evolutionary relationships among promoter sequences to identify conserved cis-regulatory motifs (Blanchette et al. 2002; Blanchette and Tompa 2002). Phylogenetic footprinting approaches have been used to identify cis-elements in a number of plant species including Populus and Eucalyptus (Creux et al. 2008; Shi et al. 2010).

While cellulose deposition during secondary cell wall formation has been extensively studied in herbaceous and woody plants (Reviewed in Taylor 2008; Popper et al. 2011; Gorshkova et al. 2012), the promoters and cis-element composition of the cellulose synthase (CesA) genes have been the focus of only a small number of studies (Creux et al. 2008; Lu et al. 2008; Wu et al. 2009). CESA proteins, encoded by the CesA gene family, form large 
membrane-embedded complexes depositing cellulose into plant cell walls (Mutwil et al. 2008). In embryophytes, this gene family forms a distinct clade consisting of 8-18 members per species (Hamann et al. 2004; Roberts and Bushoven 2007; Kumar et al. 2009; Yin et al. 2009). In plants there are two distinct Ces $A$ gene expression groups, one associated with primary cell wall formation and the other with secondary cell wall formation (Taylor et al. 2004; Desprez et al. 2007). Independent functional analyses of the $\operatorname{Ces} A$ genes in woody and herbaceous species have revealed that orthologous $\operatorname{Ces} A$ genes are functionally conserved in diverse plant species (Tanaka et al. 2003; Taylor et al. 2003; Samuga and Joshi 2004; Ranik and Myburg 2006; Kumar et al. 2009). This conservation likely includes a set of shared cisregulatory sequences and transcription factors since Ces $A$ gene expression profiles are also highly conserved across different plant genera (Burton et al. 2004; Ranik and Myburg 2006; Creux et al. 2008).

In this study we hypothesize that cis-regulatory elements will coincide with regions of lower species-level nucleotide diversity in the promoters of evolutionary distinct Eucalyptus tree species. In addition, we hypothesize that different sets of cis-elements are conserved in the promoters of primary or secondary cell wall-related CesA genes. The objectives were: i) to quantify and assess patterns of species-level nucleotide diversity in the promoters of six Eucalyptus cellulose synthase genes, ii) to assess the effects of nucleotide polymorphism on putative cis-element occurrences and iii) to identify putative cis-elements that are differentially conserved in promoters of primary and secondary cell wall-related CesA genes. This study is the first to characterize the species-level nucleotide diversity and cis-element architecture of CesA gene promoters in a plant genus and adds to our understanding of the transcriptional regulation of this important plant gene family. 


\section{Materials and Methods}

\section{Plant material and DNA isolation}

Leaf material was obtained from Eucalyptus species conservation hedges established with seed collected from natural stands in Australia (CSIRO, Online Resource 1). High quality genomic DNA was extracted from leaf material using the DNeasy® Plant Mini Kit (Qiagen, Valencia, CA). Genomic DNA was isolated from a single tree from each of 13 eucalypt species, including E. fastigata (subgenus Eucalyptus), and 12 species of the commercially important subgenus Symphyomyrtus representing three sections, Latoangulatae, Maidenaria and Exsertaria (Online Resource 1). In addition, genomic DNA was also isolated from nineteen E. urophylla individuals originating from seed collected on seven Indonesian islands (Timor, Flores, Alor, Pantar, Adonara, Lomblen and Wetar), broadly representing the geographical range of the species (Payn et al. 2008).

\section{Promoter isolation and sequencing}

Primer Designer software (version 5, Scientific and Educational Software, Durham, NC) was used to design primers (Online Resource 2) for the amplification of gene and promoter regions based on previously published E. grandis CesA gene and promoter sequences (Ranik and Myburg 2006; Creux et al. 2008). For CesA1, PCR amplification of a single gene fragment from each of the 13 Eucalyptus species, extending from the promoter to the end of intron 1, was performed (Online Resource 2). Only the promoter regions (approximately $1 \mathrm{~kb}$ upstream of the ATG) were amplified for the other five CesA genes. PCR was performed in $20 \mu 1$ reaction volumes with $30 \mathrm{ng}$ of genomic DNA, $0.4 \mu \mathrm{M}$ of each primer, $0.20 \mathrm{mM}$ of each dNTP and $0.15 \mathrm{U}$ of ExSel DNA polymerase (Supertherm) with proofreading capability (4-fold lower error rate than standard Taq polymerase, according to manufacturers) using the following conditions: 30 cycles of denaturation at $94^{\circ} \mathrm{C}$ for 30 seconds, annealing at $56^{\circ} \mathrm{C}$ for 30 seconds and primer extension at $72^{\circ} \mathrm{C}$ for 2 minutes. The amplified fragments were cloned 
(InsT/Aclone, MBI Fermentas, Hanover, MD) and a cloned copy of each promoter fragment was sequenced using overlapping Sanger reads (Macrogen Inc.), representing a single allele of each promoter from each species (Genbank accession numbers: JN573683 - JN573751).

The chromatograms were visually inspected to check the sequence quality of each base. When double, conflicting bases were identified at the same site the clone was resequenced and re-analyzed until a consensus was reached. At least $1000 \mathrm{bp}$ of upstream sequence was analysed for CesA1 to 5, while approximately 800 nucleotides of the $\operatorname{Ces} A 7$ promoter were used. The 5' upstream regions isolated from each gene started at most $25 \mathrm{bp}$ upstream of the start codon (ATG) and contained the 5' UTR and a minimum of $500 \mathrm{bp}$ of each promoter. Sequences were analysed from the ATG because the start codon of each gene has previously been experimentally verified (Ranik and Myburg 2006).

\section{Orthologous gene and promoter sequences of Arabidopsis and Populus}

Kumar et al. (2009) proposed a new phylogeny-based nomenclature for the Ces $A$ genes in poplar. Their naming convention allows for direct comparison of the Arabidopsis and Populus CesA genes (Online Resource 3). This change in nomenclature has not yet been applied to the Eucalyptus CesA genes therefore in this study we kept the naming convention used in the first study that reported the Eucalyptus CesA genes (Ranik and Myburg 2006). Online Resource 3 lists the Eucalyptus CesA genes and their orthologs in Populus and Arabidopsis. Promoter sequences of the Arabidopsis thaliana CesA orthologs (AtCesAs 1-10) were obtained from The Arabidopsis Information Resource (TAIR9, www.arabidopsis.org), and those of the Populus trichocarpa orthologs (PtiCesAs, Kumar et al. 2009) were obtained from the Populus Genome Browser (DOE JGI http://www.phytozome.net, Online Resource 3). The same set of promoter sequences were used as in the study by Creux et al (2008). Additionally, the orthologous gene sequences of Eucalyptus CesA1, AtCesA8 (At4g18780) and PtiCesA8-A (Pti235238), were obtained from the same databases. To ensure that the 
regions of the Eucalyptus CesAl gene and its orthologs could be compared, the promoter regions were trimmed to equal length (297 bp) in all orthologs. The first intron region was also trimmed (to $68 \mathrm{bp}$ ), resulting in an analysis region that included part of the proximal promoter, 5' UTR (untranslated region), exon 1 and part of intron 1 (Accession numbers JN573752 - JN573783).

\section{DNA sequence analysis}

After removal of vector sequences, DNA sequences of the Eucalyptus CesA promoters were assembled using the Vector NTI software package (version 9.1.0, Invitrogen). The sequences were aligned using the Clustal W (Thompson et al. 1994) function of BioEdit (version 7.0.9, Hall 1999). DNA sequence analysis and nucleotide diversity ( $\pi$; Nei and Li 1979) and $\theta_{\mathrm{W}}$; (Watterson 1975) calculations were performed using DnaSP (DNA Sequence Polymorphism, version 4.50.3, Rozas et al. 2003). The distribution of nucleotide diversity in the sequences was graphically represented using per site sliding windows of $\pi$. Nucleotide diversity was represented by the average of a moving window of $50 \mathrm{bp}$ for Figure 1 and a sliding window of $100 \mathrm{bp}$ (grey line) with a moving average (black line) fitted to each graph in Figure 2.

\section{Cis-element selection}

We focused on 22 previously reported, putative cis-elements, most of which have not been functionally characterized, and we refer to these from this point forward as cis-elements without ascribing any functional annotation (Table 1). First, putative cis-elements were selected based on their over-representation in CesA promoters associated with primary (CRPE17, CRPE 12, CRPE 11, CRPE 10, CRPE8, CRPE6) or secondary (CRPE31, CRPE28, CRPE26, CRPE25) cell wall formation, as identified in a comparative study of Eucalyptus, Arabidopsis and Populus CesA promoters (Creux et al. 2008). A second set of cis-elements was identified by using the PLACE database homology search tool (http://www.dna.affrc.go.jp/PLACE/, Higo et al. 1999). Cis-elements with motif lengths of 
greater than five base pairs were selected if they were present in the promoters of all three primary or all three secondary cell wall-related $\operatorname{Ces} A$ genes (Table 1). The xylem-specific promoter element identified by Ko et al (2006) and the tracheary element-specific motif identified by Pyo et al (2007) were also added to the set of cis-elements as they have been suggested to play a role in secondary cell wall formation in Arabidopsis.

\section{Cis-element mapping}

Pattern Matching in RSA-Tools (http://rsat.scmbb.ulb.ac.be/rsat/; Thomas-Chollier et al. 2008) was used to map occurrences of the selected cis-elements onto the six CesA promoter sequences of each of 13 Eucalyptus species. Pattern matching and image generation were conducted using the default settings. A random data set was generated using RSA-Tools Random Sequence Generator, which calibrated the sequences on Arabidopsis non-coding upstream sequences. An Arabidopsis-specific Markov model was used to generate the random sequences. In order to visualise the cis-element maps generated by RSA Tools (Figure 3) in a meaningful way so that patterns of cis-element conservation and variation could be more easily observed we concatenated the promoter sequences from each gene together per species. These sequences were then used to construct a preliminary neighbour joining tree in MEGA (Tamura et al. 2011) and the species order was used to arrange the promoters during cis-element mapping (Figure 3). Promoter sequences containing the mapped cis-elements were divided into discrete $100 \mathrm{bp}$ intervals (i.e. -1 to $-100,-101$ to -200 , etc.), and cis-element occurrences in each section were counted and graphically represented in comparison with the random data set. A two-tailed t-test assuming equal variance was performed, to identify regions that showed significant differences from the random dataset with $\alpha=0.01$ and $\alpha=0.001$. Motif logos were generated using the output sequences from RSA-Tools in the online motif logo tool, Weblogo (http://weblogo.berkeley.edu/logo.cgi),

with all default settings (Schneider and Stephens 1990; Crooks et al. 2004). The Eucalyptus- 
specific motif logos were compared to the cis-element consensus logos generated across all three genera (Arabidopsis, Populus and Eucalyptus) using the same tools (Online Resource $4)$.

\section{Cis-element conservation analysis}

Cis-element conservation was estimated by counting the number and type of nucleotide changes that occurred within cis-element occurrences (Online Resource 5 and 6). The ciselement occurrences could be grouped into three categories: conserved cis-element occurrences, where no changes were observed in any of the Eucalyptus species analysed; moderately conserved cis-element occurrences, where only a single position in the ciselement sequence was changed in one or more species; and non-conserved cis-element occurrences, where more than one position in the cis-element sequence was changed in one or more of the species analysed. The types of nucleotide changes were also classified as singletons (occurring in only one of the 13 species), or polymorphisms (occurring in two or more species). The different cis-element and mutation counts were entered into Excel (Microsoft Office 2007), where the averages and percentages of the different polymorphism affecting cis-element occurrences were calculated (Online Resource 6).

\section{Results}

Sequence divergence and nucleotide diversity of the Eucalyptus CesA1 gene and promoter at the population, species and genus levels

We compared the nucleotide diversity of the proximal promoter and 5' regions (ATG was the anchor point placed at position $0 \mathrm{bp}$ ) of the secondary cell wall-related Eucalyptus CesA1 gene (Ranik and Myburg 2006), including representative portions of the 5' UTR, first exon and first intron to the orthologous cellulose synthase genes of Arabidopsis and Populus (Figure 1). Nucleotide diversity in these regions was calculated for three sets of sequences:

(1) the genus-level comparison of the E. urophylla CesAl gene to its Arabidopsis and 
Populus orthologs (Online Resource 3), (2) the species-level comparison of the CesA1 gene sequences from thirteen Eucalyptus species (Online Resource 1) and finally, (3) a populationlevel comparison which included sequences from a population sample of 19 E. urophylla trees (Figure 1). As expected, the average nucleotide diversity over the whole $611 \mathrm{bp}$ region was highest for the genus-level comparison $(\pi=0.461)$, which was close to a value expected for unrelated sequences (Figure 1, green trend line). The Eucalyptus species- and populationlevel comparisons exhibited significantly lower average diversity $(\pi=0.015$ and $\pi=0.006$, respectively) in the same region. The observed nucleotide diversity at the population level (Figure 1, black trend line) was generally below $1 \%$ and the diversity observed in parts of the promoter and first exon was due to single nucleotide polymorphisms (SNPs). The nucleotide diversity of the promoter was higher at the species-level (Figure 1, red trend line), but distinct regions of relative sequence conservation were observed within the promoter region (Figure 1, black arrows). These results demonstrate that at the genus-level, the promoters are too divergent structurally to observe conserved sequence elements by direct sequence comparison. Conversely, the population-specific comparison suggested that the sequences were too similar to identify defined regions of conservation. The species-level comparison, however, did reveal conserved regions in the promoters, which may contain clusters of cisregulatory elements and the other five CesA promoters (CesA2, 3, 4, 5 and 7) were consequently investigated at this level.

\section{Isolation and analysis of the CesA1-5 and 7 promoter regions of 13 Eucalyptus species}

The upstream regions of six CesA genes (EgCesA1-5: Ranik and Myburg 2006; EgCesA7: Creux et al. 2008) were isolated from one individual of each of 13 Eucalyptus species and used to investigate detailed patterns of sequence and spatial conservation of selected, putative cis-elements among the Eucalyptus species (sequence alignment, Online Resource 5). Creux et al (2008) showed that E. grandis CesA4 had an intron in the 5'UTR and this intron was 
also present in the CesA4 promoter of the other 12 Eucalyptus species investigated here indicating conservation in the 5'UTR in the gene. It is well documented that 5' UTR sequences and the associated introns can play important roles in cis-regulation (Karthikeyan et al. 2009; Livny and Waldor 2009). For this reason, we disregarded promoter/ UTR boundaries and in all instances, the entire upstream regions including the 5' UTR (and intron in the case of $\operatorname{Ces} A 4$ ) were analysed for regulatory element occurrence and conservation.

Despite several rounds of primer optimisation and design, we were unable to isolate the upstream regions of the CesA5 gene from E. camaldulensis, E. tereticornis and E. dunnii presumably due to high sequence divergence in the upstream priming sites. Amplification of the E. fastigata CesA5 promoter was only achieved when the primers were moved immediately upstream of the original binding sites, which were subsequently found to contain E. fastigata-specific sequence polymorphisms (primer sequences, Online Resource 2). As a result, the CesA5 promoter dataset only contained sequences from ten Eucalyptus species. Furthermore, two distinct sequence haplotypes of the CesA 5 promoter were observed among the ten Eucalyptus species analysed (Online Resources 4 and 5). Species from the subgenus Eucalyptus (E. fastigata) and Symphyomyrtus section Latoangulatae (E. grandis, E. urophylla and E. saligna) shared a single haplotype. The second haplotype was only observed in species of the section Maidenaria (E. macarthurii, E. globulus maidenii, E. globulus globulus, E. globulus bicostata, E. smithii and E. nitens, Online Resources 4 and 5). PCR amplification with haplotype-specific primers confirmed that the two putative haplotypes do not co-occur within any of the eucalypt species analysed and are therefore not likely to be derived from paralogous sequences in the Eucalyptus genome (data not shown).

There are 11 expressed CesA genes in Eucalyptus (Mizrachi et al. 2010) and to ensure that no duplicate promoters were isolated all of the CesA promoter sequences analysed in this study were compared to the E. grandis genome sequence (DOE JGI, 
http://www.phytozome.net). In all cases the sequences matched a single region directly upstream of the corresponding CesA gene, supporting our inference that no paralogous promoters were isolated. Sequence comparison of the two CesA5 promoter haplotypes with the genome sequence also confirmed that the two haplotypes correspond to the promoter regions of a single CesA5 gene locus in the E. grandis genome (data not shown, Phytozome gene ID: Eucgr.C02801.1).

\section{Species-level sequence diversity in the promoter regions of the Eucalyptus Ces $A$ genes}

The average species-level nucleotide diversity $(\pi)$ of the six Eucalyptus CesA promoter regions varied from $\pi=0.014$ for $\operatorname{Ces} A 7$ to $\pi=0.068$ for $\operatorname{Ces} A 5$ (Table 2). The high specieslevel nucleotide diversity observed in the CesA5 promoter regions could be ascribed to the presence of the two distinct haplotypes (Online Resource 5 and 7). In all of the promoters a local decrease in nucleotide diversity across species was observed at the transcriptional start site (Figure 2, shaded boxes). Additionally, in the $\operatorname{Ces} A 1,2,3,4$ and 7 promoters there were regions further upstream where local species-level diversity was below $\pi=0.02$, which is the nucleotide diversity expected for conserved coding regions and could indicate functional constraints within these regions (Figure 2).

\section{Cis-element position and frequency in the promoter regions of the Eucalyptus CesA genes}

We investigated the positional conservation of cis-elements in the CesA promoter regions by mapping occurrences of 22 previously identified putative cis-elements (Table 1) in the promoter sequences of 13 Eucalyptus species (Figure 3 and Online Resource 5). Three of the cis-elements (CRPE25, CRPE26 and TERE;Table 1) could not be found in any of the 13 Eucalyptus CesA promoter sequences, even when mismatches were allowed, but they were detected in the Arabidopsis and Populus orthologs (Figure 3). The CRPE11 cis-element could not be identified in any of the sequences analysed and may represent a false positive result 
from the previous study. Cis-element occurrence counts revealed regions with a significantly higher/lower number of occurrences in the promoter sequences, while an even cis-element distribution was observed in the random dataset (Figure 4). The occurrences of each ciselement in the Eucalyptus CesA promoters were used to generate Eucalyptus-specific ciselement consensus sequences which were very similar at the species- and genus-level, even in sites allowing for alternative bases (Online Resource 4).

Mapping the cis-element occurrences to the promoter regions (Figure 3 and Online Resource 5) allowed us to evaluate the cis-element content of conserved promoter regions (Figure 2). In each of the Eucalyptus promoters, a set of co-occurring elements (Figure 3, transparent grey blocks) was identified near the previously predicted TSSs (Creux et al. 2008). This set of putative cis-elements comprised multiple occurrences of the CRPE31 (GNGNAGNA, Figure 3: orange) and CTRMCAMV35S (TCTCTCTCT, Figure 3: purple) motifs with the exception of CesA3 where only CRPE31 occurred approximately $200 \mathrm{bp}$ upstream of the predicted TSS (Figure 3). These were not conserved in the Arabidopsis and Populus promoters (Figure 3). In CesA7, however, the cluster and region of lower specieslevel nucleotide diversity was located further upstream (-450 to -300$)$ of the TSS and may indicate that the predicted TSS for this gene should be re-evaluated. The TATABOX 5 element (TTATTT, Figure 3: pink), from the PLACE database, was the only TATA-box-like sequence identified in the Eucalyptus CesA promoters. In the CesA1, 5 and 7 promoters, the putative TATA-box-like motif was found far upstream (400 to $1000 \mathrm{bp}$ ) from the TSS (Figure 3).

The cis-element maps also enabled us to observe positional conservation of ciselement combinations. MYB1AT (WAACCA, Figure 3: black) and NODCON1GM (AAAGAT, Figure 3: brown) were found to co-occur in the secondary cell wall-related CesA promoters within $200 \mathrm{bp}$ of each other (Figure 3A, B and C). These two putative cis-elements 
also appeared to be positionally conserved within these promoters as they were always observed in the region between -200 to -600 bp upstream of the TSS in CesA1, 2 and 3 (Figure 3D, E and F).

\section{Cis-element evolution in the promoter regions of the Eucalyptus Ces $A$ genes}

To investigate the potential effect of DNA sequence evolution on cis-element occurrences in Eucalyptus, all of the putative cis-element occurrences in the Eucalyptus CesA promoters were investigated for sequence conservation. The individual cis-element occurrences were scored as conserved if no polymorphism occurred in the region across all 13 promoter sequences (Figure 5A and Online Resource 6). Putative cis-element occurrences that had a single nucleotide polymorphism (present in two or more cloned sequences) relative to the Eucalyptus consensus sequence (Online Resource 4) and those that had two or more nucleotide changes away from the consensus sequence were counted separately (Figure 5A and Online Resource 6). Overall, only $29 \%$ of the cis-element occurrences investigated were fully conserved in the 13 Eucalyptus promoter sequences. The Eucalyptus CesA1 promoters had the highest number of fully conserved cis-element occurrences (59\%), while CesA5 had the lowest at $13 \%$ (Figure $5 \mathrm{~A}$ ).

We identified 89 instances ( $42 \%$ of all occurrences) where a putative cis-element occurrence was present or absent in all but one of the 13 promoters (Online Resource 6). These instances were classified as singleton (gain or loss) occurrences and $70 \%$ of these resulted from single nucleotide changes, while $30 \%$ were due to indels (Figure 5B). Some of the single nucleotide changes could have resulted from cloned PCR errors, however the observed frequency of singletons was approximately ten times higher than would be expected from polymerase induced errors (average $1 \times 10^{-4}$ per base pair; Keohavong and Thilly 1989; Ling et al. 1991). We investigated the frequency of singleton mutations that resulted in a change towards the consensus sequence (i.e. a change that rendered the cis-element 
identifiable by the software in that promoter) or away from the consensus sequence (i.e. a change rendering the consensus sequence unidentifiable by the software). The majority of sequence changes $(72 \%$ of the SNPs and $71 \%$ of the indels, Figure $5 \mathrm{~B})$ resulted in a change towards the cis-element consensus sequence (Online Resource 4) and therefore may indicate a gain (or maintenance) of the cis-element occurrence in that species. However, to accurately investigate this, more individuals should be sequenced for each species and experimentally verified Eucalyptus cis-elements, which are not yet available, should be used.

\section{Discussion}

CesA gene family members have conserved roles in the deposition of primary and secondary cell walls in all seed plants studied to date (Burn et al. 2002; Burton et al. 2004; Hamann et al. 2004; Ranik and Myburg 2006). This suggests that the major clades of the gene family differentiated early during Spermatophyte evolution (Sarkar et al. 2009; Yin et al. 2009; Popper et al. 2011). A distinctive set of expression patterns characterize the major clades with CesA genes involved in primary and secondary cell wall deposition exhibiting unique, developmentally regulated expression profiles (Hamann et al. 2004). The conserved nature of these genes and their highly coordinated, but differential, expression patterns point to the action of a conserved network of cis- and trans-regulatory factors in plants (Demura and Fukuda 2007; Zhong et al. 2010). The aim of this study was to characterize the architecture and diversity of cis-elements in six CesA promoters across Eucalyptus tree species in terms of sequence and cis-element conservation.

Nucleotide diversity levels are generally higher in promoter regions than in other genic regions, most likely due to lower overall functional constraints on promoter regions (Nei 2007). That said, the maintenance of functional cis-elements in promoter regions and the modular nature of transcription factor binding suggests that there should be localised regions 
that are more conserved than the rest of the promoter and contain clusters of cis-elements (Maniatis et al. 1987; Ho et al. 2009). To determine whether this is the case for CesA genes, we compared nucleotide diversity levels in different CesAl gene regions at the population, species and genus levels. While the nucleotide diversity in the genus and population levels were at the highest and lowest extremes of the scale respectively, the diversity at the species level showed a large range of values from $1.4 \%$ to $6.8 \%$ (Figure 1). At the species level the nucleotide diversity plot profile revealed that the higher nucleotide diversity in the upstream regions was interrupted by areas with distinctly lower nucleotide diversity (Figure 1 - red line and arrows). In a similar study on the Drosophila bithorax complex, Ho et al (2009) also identified regions of conservation across orthologous promoters in different Drosophila species and could suggest that short conserved sequences are a feature of related eukaryotic promoters.

The conservation of promoter sequences has been documented for a number of different plant species, but sequence conservation in promoter regions may not always indicate cis-element conservation (Reineke et al. 2011). In light of this, we evaluated the occurrences of previously identified cis-elements (Table 1) in the cloned Eucalyptus promoter sequences. We found that $76 \%$ of the cis-element occurrences were either fully conserved (29\%) in the 13 Eucalyptus promoters or only varied from the consensus sequence by a single nucleotide change (47\%, Figure $5 \mathrm{~A}$ and Online Resource 6$)$. In this study the ciselement occurrences which are affected by one nucleotide change are likely also to be conserved elements because cis-element consensus sequences often contain some ambiguous bases and transcription factors can still bind to these variable sites.. The cis-element occurrences with a single change could also be more conserved than estimated here since the changes may be due to allelic variation within the different populations, but this variation 
would have to be further investigated in these different populations when a core set of experimentally tested cis-elements are available for Eucalyptus.

Identifying conserved cis-elements or regions in the promoter does not fully describe the spatial arrangement of these elements, which is important because cis-elements are often found clustered together, rather than evenly distributed across the length of the promoter (Maniatis et al. 1987; Hansen et al. 2010). We found that there was strong clustering of ciselements at particular intervals in the promoters when compared to neighbouring intervals or to a random dataset (Figure 4). A significant cluster of cis-elements was observed at the position of the TSS in a number of the CesA promoters (Figure 4: $\operatorname{Ces} A 1,4,5$ and 7), and the position of this cis-element cluster (TSS-associated cluster) also coincided with a highly conserved promoter region (Figure 2; transparent grey blocks). In a genome-wide comparative study of Populus and Arabidopsis a number of conserved cis-element clusters were also identified in the promoters of genes associated with cellulose deposition (Ding et al. 2012) and this could indicate functional constraints acting on the particular CesA promoter regions.

The TSS-associated cluster of cis-elements identified in five of the six Eucalyptus CesA promoters (except CesA3) contained multiple occurrences of two cis-elements CRPE31 and CTRMCAMV35S (Figure 3: purple). CRPE31 (GNGNAGNG, Figure 3: orange) was the most abundant cis-element detected in the Eucalyptus promoters as well as in a previous ciselement study of CesA promoters (Creux et al. 2008). The reverse compliment sequence of this element (CNCTNCNC) could be an initiator element similar to the elements described in Arabidopsis (Bernard et al. 2010). The initiator element has been shown to co-occur with the TSS in the promoters of different plant species (Yamamoto et al. 2007) and this may suggest a function for these putative CRPE31 occurrences in the Eucalyptus promoters. 
The other main element in the TSS-associated cluster was the CTRMCAMV35S element (TCTCTCTCT, Figure 3: purple). In the PLACE database, this element is listed as an enhancer found in the commonly used Cauliflower Mosaic Virus (CAMV) 35S viral promoter (Pauli et al. 2004). This element is highly over-represented in the CesA promoters in the form of TC-repeats (Online Resource 5). Multiple copies of the CTRMCAMV35S element could enhance the expression of the CesA genes which would be of interest because these are some of the most highly expressed Eucalyptus genes (Mizrachi et al. 2010). Alternatively, the CTRMCAMV35S repeats could represent plant-specific regulatory regions known as Y-patches (CT or TC repeats) which have been associated with the TSSs of other plant promoters in genome-wide studies of Arabidopsis and rice (Molina and Grotewold 2005; Yamamoto et al. 2007). The putative CRPE31 and CTRMCAMV35S element occurrences in this conserved TSS-associated cluster may play a role in the initiation of transcription of a number of the Eucalyptus CesA genes.

The suggestion that transcriptional initiation of the Eucalyptus CesA genes could be reliant on the presence of putative initiator (CRPE31) and Y-patch (CTRMCAMV35S) elements is further bolstered by the lack of a TATA-box in many of the Eucalyptus CesA promoters (Figure 3). The only over-represented element resembling a TATA-box (PLACE ID: TATABOX5; TTATTT) was found in a subset of the CesA4 promoter sequences in the correct location (Figure 3: pink). This TATA-box-like element was also identified in the Eucalyptus CesA1, 4, 5 and 7 promoters, but its position in each instance was $\geq 600$ bp upstream of the TSS (Figure 3, pink) and did not coincide with any major decrease in species-level nucleotide diversity. This suggests that these sequences do not function as TATA-boxes, because in the original description of this element it was functional when located 50 bp upstream of the TSS (Tjaden et al. 1995). Additional support for this TSSassociated cluster comes from our previous study which reported some of the Eucalyptus 
grandis CesA promoters, which contain the TSS-associated cluster, to be TATA-less. However, the promoter fragments were still able to drive tissue-specific expression of the GUS reporter gene in Arabidopsis and had experimentally verified TSSs (Creux et al. 2008).

Further upstream of the TSSs, other putative cis-elements could be observed as singletons, pairs or clusters in the CesA promoters (Figure 3). One example of this is the cooccurrence of the NODCON1GM (AAAGAT, Figure 3: dark brown) and MYB1AT (WAACCA, Figure 3: black) elements in the CesA promoters of the genes associated with secondary cell wall deposition. In CesA1, 2 and 3, the elements co-occurred in the region between -200 and $-600 \mathrm{bp}$, and this positional conservation was not observed in the promoters of the $\operatorname{Ces} A$ genes associated with primary cell wall formation (Figure 3 ). This suggests that NODCON1GM and MYB1AT may play a role in secondary cell wall-specific expression of these genes.

The putative MYB1AT occurrences in CesA1, 2 and 3 were of special interest for a number of reasons. Yazaki et al. (2003) found the MYB1AT element to be involved in Arabidopsis dehydration stress response while investigating gibberellic acid (GA) and abscisic acid (ABA) responses in rice. GA has also been found to play a role in cambial cell differentiation and xylem development (Love et al. 2009) pointing to the co-regulation of genes involved in xylogenesis. This putative MYB-like element may also be important as a number of MYB transcription factors have been identified as key members of the transcriptional network regulating the secondary cell wall formation (Goicoechea et al. 2005; Demura and Fukuda 2007; Legay et al. 2010; Zhong et al. 2010).

While many of the putative cis-element occurrences investigated in this study were conserved in the promoters of the different Eucalyptus species, a small number of occurrences varied among species (Figure 5B). We counted 89 singleton changes (i.e. loss or gain of an occurrence in only one of the 13 sequences) in the Ces $A$ promoters and $66 \%$ of the 
sequence polymorphisms changed the promoter sequence towards a known cis-element consensus sequence (Online Resource 6). One hypothesis for this cis-element variation is known as cis-element buffering, which ensures the maintenance of a particular cis-element sequence in faster evolving sequences such as promoters (Tanay et al. 2005). It proposes that the promoter sequence may change to abolish a particular cis-element occurrence, but a second mutation in that promoter maintains the binding site of a particular transcription factor. This mechanism of cis-element maintenance has been observed in the cis-regulatory modules of a number of Drosophila genes (Hare et al. 2008; Ho et al. 2009) and could be a mechanism of maintenance in the Ces $A$ gene promoters, but this can only be confirmed by further investigation on both the population-wide and genome-wide level with experimentally verified cis-elements from Eucalyptus.

An interesting observation form this study was that, while most of the Eucalyptus Ces $A$ promoters were similar in terms of GC content and number of indels, the Ces $A 5$ promoters were distinct. The CesA5 promoter dataset had the lowest GC content (36\%) and more than double the number of indels than the other promoters (Table 2). CesA5 also presented with the lowest number of conserved cis-element occurrences (Figure 5A). Sequence analysis revealed at least two CesA5 promoter haplotypes in the Eucalyptus dataset and these were congruent with the different sections of Symphyomyrtus in which they occurred (Online Resources 1 and 5). The promoter regions of species belonging to the section Exsertaria (E. camaldulensis and E. tereticornis) could not be amplified and might represent yet another haplotype. It appears that the distal part of the CesA5 promoter is undergoing rapid divergence, and the pattern of divergence is in keeping with the phylogeny of the Eucalyptus species. Since haplotype 1 is shared among representatives of both subgenera, it is likely to be ancestral and the alignment of the CesA5 promoter sequences (Online Resources 4 and 5) suggests that multiple insertional events have occurred. The high 
sequence divergence observed in the distal region (upstream from $-390 \mathrm{bp}$ ) suggests that the proximal region of the CesA5 promoter may harbour most of the essential cis-elements for this gene.

\section{Conclusions}

This is one of only a few studies that have investigated sequence diversity in the promoters of a plant gene family (Koch et al. 2001; de Meaux et al. 2006; Tanaka et al. 2009; Zhao et al. 2009). We identified regions within the CesA promoters that are conserved across Eucalyptus species and coincided with the putative occurrences of cis-elements, suggesting that they have important biological functions. Overall, we found that $29 \%$ of the investigated cis-element occurrences were fully conserved in Eucalyptus CesA genes. Only 30\% of the singleton changes were away from the consensus sequence (Figure 5B), suggesting there are functional constraints on some sequences within the promoter regions. The CesA promoters of Eucalyptus appear to be TATA-less and a highly conserved region in these promoters was identified in the vicinity of the TSSs, suggesting that the basal transcriptional machinery for this Eucalyptus gene family relies on other basal cis-elements such as a putative initiator element and Y-patch to initiate transcription. Conserved cis-elements were also found in the promoters of the CesA genes associated with secondary cell wall formation. These were not present in the primary cell wall-associated CesA promoters. The study provides insight into the diversity and evolution of cis-regulatory sequences underlying the unique expression profiles of this important plant gene family and will lay the foundation for future studies of the function of these promoter regions and for comparative genomic analysis of promoter elements across multiple Eucalyptus genomes. 


\section{Acknowledgements}

The authors would like to acknowledge Alisa Postma for her contribution to the preliminary study leading to this research and Dr. Albe van der Merwe and Dr. Christine Martiz-Olivier for comments and guidance during the preparation of the manuscript. This work was supported with funding provided by Mondi and Sappi, through the Forest Molecular Genetics (FMG) Programme, the Technology and Human Resources for Industry Programme (THRIP) and the National Research Foundation of South Africa (NRF). 


\section{Tables}

Table 1. Details of 22 cis-regulatory elements selected from literature and PLACE database scans and used for DNA pattern matching

\begin{tabular}{|c|c|c|c|}
\hline Source $^{a}$ & Motif Identity $^{b}$ & Motif Sequence $^{c}$ & PLACE Annotation $^{\mathrm{d}}$ \\
\hline \multicolumn{4}{|c|}{ Primary cell wall-associated motifs ${ }^{e}$} \\
\hline Creux et al. (2008) & CRPE 17 & GTCKGT & Unknown \\
\hline Creux et al. (2008) & CRPE12 & ATNWATTA & Phosphate response domain \\
\hline Creux et al. (2008) & CRPE11 & GACNGTSNGTGGGC & Stem enhancer element \\
\hline Creux et al. (2008) & CRPE10 & CCNCMCCC & Vascular-specific expression \\
\hline Creux et al. (2008) & CRPE8 & GGNGGTGG & Anthocyanin regulatory element \\
\hline Creux et al. (2008) & CRPE6 & NMTTCTGTC & Iron deficiency responsive element \\
\hline Place DB & CAREOSREP1 & CAACTC & Gibberellin up-regulated proteinase expression \\
\hline Place DB & DRE2COREZMRAB17 & ACCGAC & Drought-responsive element \\
\hline Place DB & RBCSCONSENSUS & AATCCAA & Light-regulated expression \\
\hline Place DB & TATABOX5 & TTATTT & Functional TATA element \\
\hline Place DB & SEF4MOTIFGM7S & RTTTTTR & Beta-conglycinin enhancer \\
\hline \multicolumn{4}{|c|}{ Secondary cell wall-associated motifs ${ }^{e}$} \\
\hline Creux et al. (2008) & CRPE31 & GNGNAGNG & Unknown \\
\hline Creux et al. (2008) & CRPE28 & NNGCATGC & Iron deficiency response element \\
\hline Creux et al. (2008) & CRPE26 & TCCTGCYG & Unknown \\
\hline Creux et al. (2008) & CRPE25 & RCYSTGCCC & Phloem-specific expression \\
\hline Place DB & CTRMCAMV35S & ТСТСТСТСТ & Enhancer of gene expression \\
\hline Place DB & REALPHALGLHCB21 & AACCAA & Phytochrome regulatory elements \\
\hline Place DB & PYRIMIDINEBOXOSRAMY1A & ССТTTТ & Pyrimidine box involved in sugar repression \\
\hline Place DB & NODCON1GM & AAAGAT & Organ-specific element \\
\hline Place DB & MYB1AT & WAACCA & Activation draught and $\mathrm{ABA}$-induced expression \\
\hline Pyo et al. (2007) & TERE & CTTNAAAGCNA & Tracheary element-specific expression \\
\hline Ko et al.(2006) & XYLAT & ACAAAGAA & Xylem-specific \\
\hline
\end{tabular}

${ }^{\mathrm{a}}$ Original source of the cis-element

${ }^{\mathrm{b}}$ Published name or identity of the cis-element

${ }^{\mathrm{c}}$ Published consensus sequences for the cis-element motifs with ambiguous bases represented as

IUPAC codes where $\mathrm{W}=\mathrm{A} / \mathrm{T}, \mathrm{M}=\mathrm{A} / \mathrm{C}, \mathrm{R}=\mathrm{A} / \mathrm{G}, \mathrm{K}=\mathrm{T} / \mathrm{G}, \mathrm{S}=\mathrm{G} / \mathrm{C}, \mathrm{Y}=\mathrm{C} / \mathrm{T}$ and $\mathrm{N}$ represents any of the four bases.

${ }^{\mathrm{d}}$ Putative function of the cis-elements as reported in literature or the PLACE database.

e The cis-element motifs were assigned as primary or secondary cell wall-associated based on the study in which they were first identified and/ or the description on the PLACE database. 
Table 2. Species-level nucleotide diversity in the promoter regions of six cellulose synthase (CesA) genes cloned from 13 Eucalyptus tree species

\begin{tabular}{|c|c|c|c|c|c|c|}
\hline & CesA1 & CesA2 & CesA3 & CesA4 & CesA5 & CesA7 \\
\hline Number of species analysed & 13 & 13 & 13 & 13 & $10^{b}$ & 13 \\
\hline Length of aligned sequence (including gaps) & 1132 & 1284 & 1317 & 1286 & 1970 & 863 \\
\hline $\mathrm{G}+\mathrm{C}$ content $(\%)$ & 43 & 47 & 45 & 47 & 36 & 53 \\
\hline Total number of sites (excluding gaps) & 989 & 1048 & 1238 & 1168 & 1260 & 730 \\
\hline Number of polymorphic sites & 66 & 134 & 93 & 105 & 253 & 51 \\
\hline Total number of singleton sites & 72 & 138 & 95 & 110 & 261 & 52 \\
\hline Nucleotide diversity $(\pi)$ & 0.018 & 0.029 & 0.018 & 0.021 & 0.068 & 0.014 \\
\hline Nucleotide diversity $\left(\theta_{\mathrm{W}}\right)$ & 0.023 & 0.042 & 0.025 & 0.030 & 0.073 & 0.023 \\
\hline Total number of insertions and deletions (indels) ${ }^{\mathrm{a}}$ & 4 & 6 & 3 & 6 & 15 & 9 \\
\hline
\end{tabular}

${ }^{a}$ Including repeat regions and indels of varying lengths occurring in more than one species analysed.

${ }^{\mathrm{b}}$ The $C e s A 5$ promoter region could only be isolated from 10 species. 
Figures

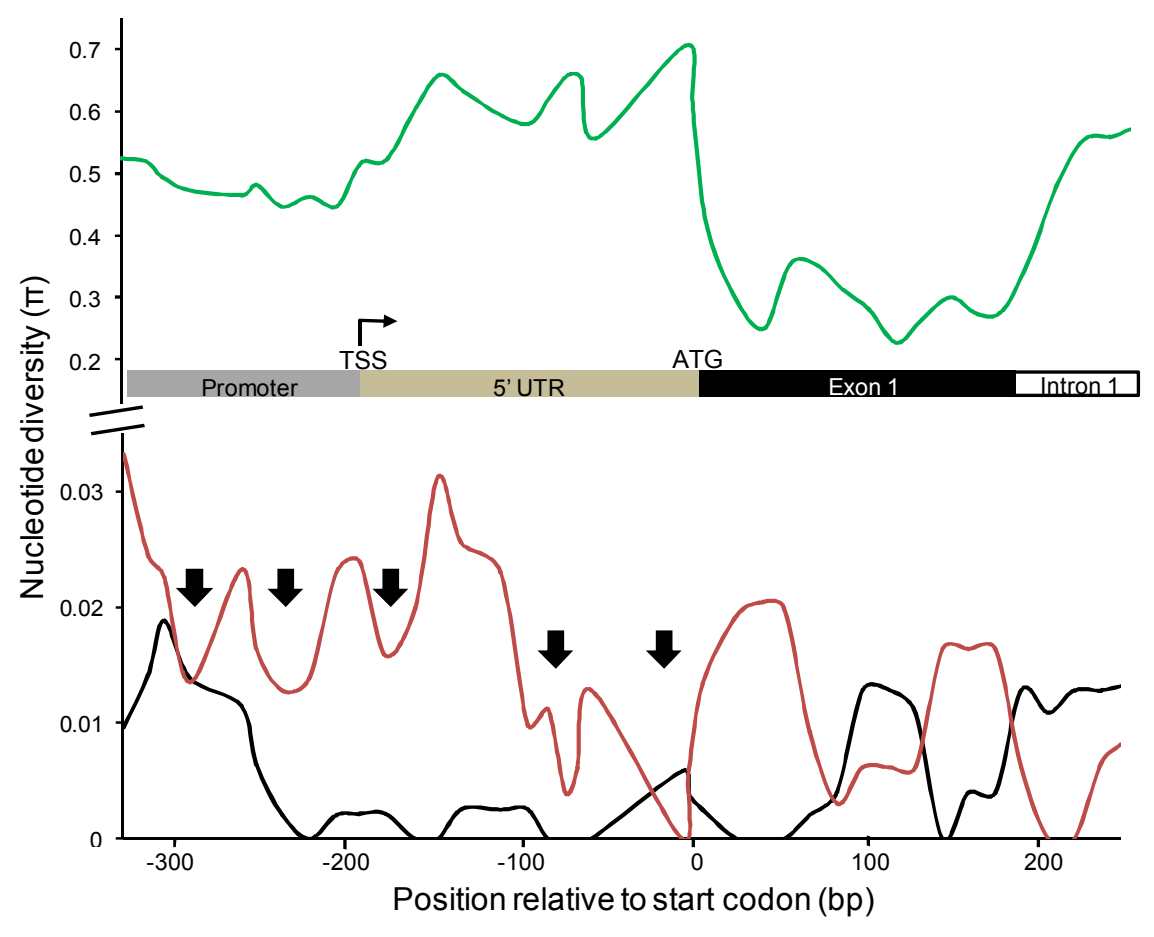

Figure 1. Nucleotide diversity $(\pi)$ in the proximal promoter and gene regions surrounding the translational start site of the Eucalyptus CesAl gene (orthologous to CesA8 in Arabidopsis and Populus) at the genus, species, and population levels (Accession numbers: JN573752 - JN573783). The gene regions are depicted by the horizontal bar at the centre of the graph. Nucleotide diversity among Eucalyptus urophylla CesA1 and its Arabidopsis thaliana (AtCesA8: At4g18780, TAIR9 www.arabidopsis.org) and Populus trichocarpa (PtiCesA8-A: Pti235238; Kumar et al. 2009) orthologs is shown in green. Nucleotide diversity in the corresponding regions of the CesAl gene from thirteen Eucalyptus species is shown in red, while nucleotide diversity in the CesAl gene from a population of E. urophylla trees is shown in black. In each case, nucleotide diversity is represented by the average of a moving window of $50 \mathrm{bp}$, calculated in DnaSP (DNA Sequence Polymorphism, version 4.50.3, Rozas et al. 2003). The black arrows indicate promoter and 5' UTR regions with lower nucleotide diversity for the species comparison (red line) indicating putatively informative regions of conservation. TSS transcriptional start site, ATG - translational start site. 

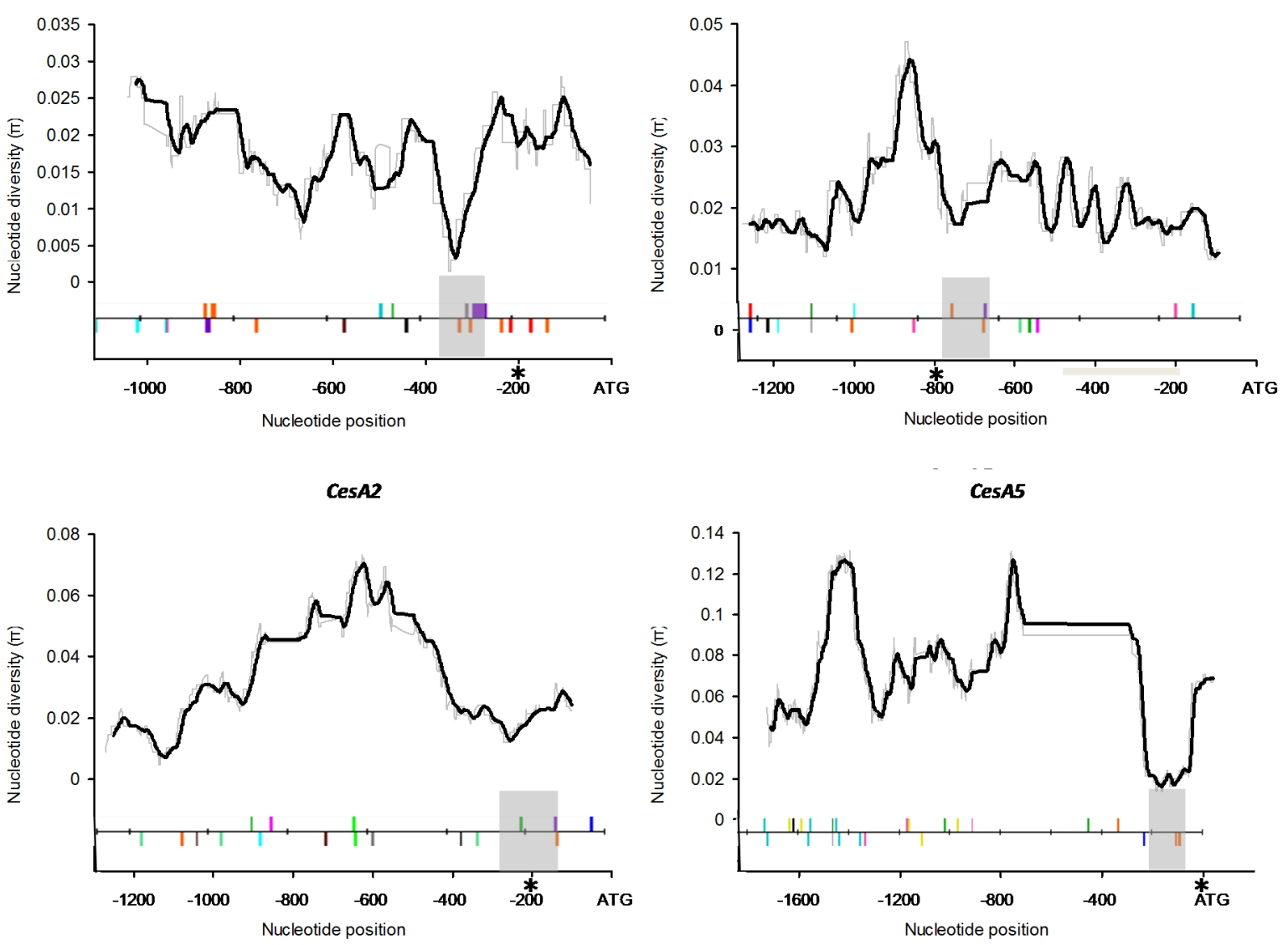

CesA3

CesA7
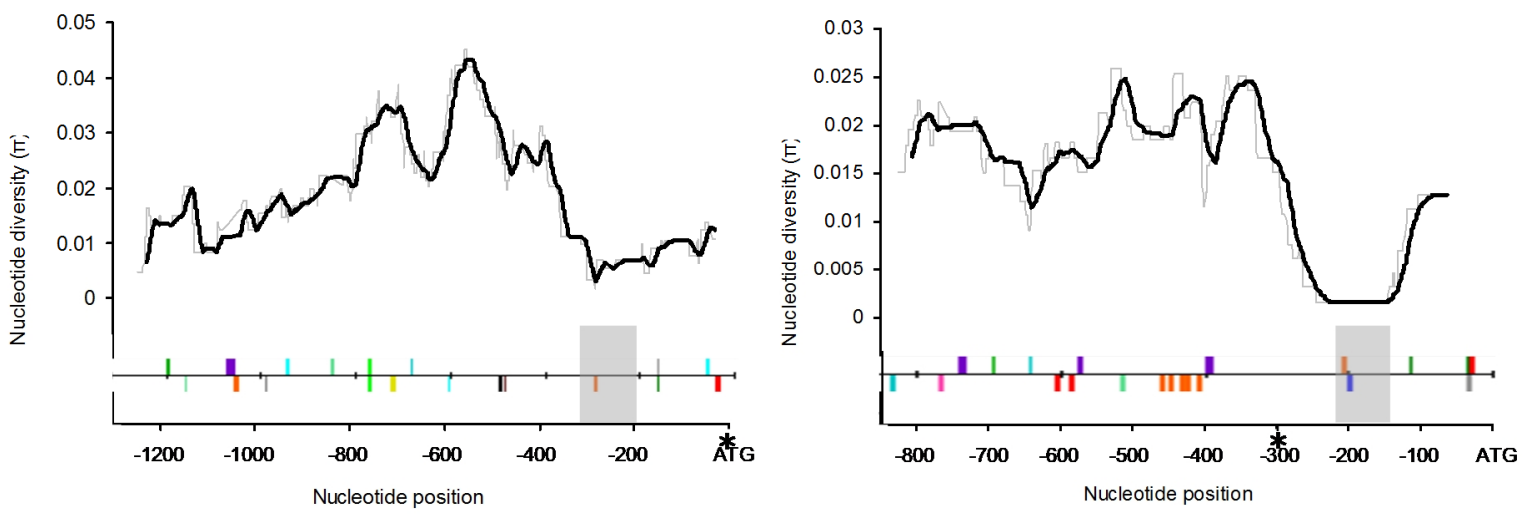

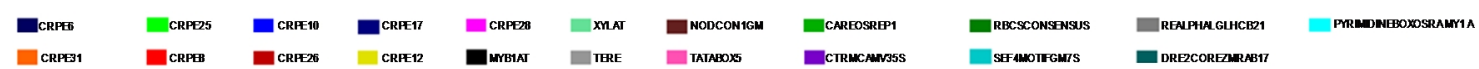

Figure 2. Nucleotide diversity profiles of the promoter regions of six cellulose synthase $(\operatorname{Ces} A)$ genes in 13 Eucalyptus species and mapped positions of putative cis-elements in these regions. Nucleotide diversity $(\pi)$ was measured per site in a sliding window of $100 \mathrm{bp}$ (grey line) with a moving average (black line) fitted to each graph as calculated in DnaSP (DNA Sequence Polymorphism, version 4.50.3, Rozas et al. 2003). Nucleotide position is indicated relative to the start of translation (ATG, +1$)$. The putative transcriptional start site (TSS) is indicated by an asterisk in each graph. A conserved intron present in the 5' UTR of CesA4 is indicated with a grey bar. The line and coloured blocks at the bottom of each graph show the position of the mapped cis-element occurrences in the $E$. grandis reference sequence. A cis-element colour key is at the bottom of the figure. The transparent grey blocks represent the position of the TSS-associated cis-elements associated with regions of lower nucleotide diversity. 
E.globulus tiscda CesA1 Eglobulus mideriicesA1 E.globulus gotutus CesA
E.macarthuri CesAT Enitens CesA1 Esmithii CesA? E.ounnII CesAI

Esaligna CesAt

Europhylla CesA1

E.grandis CesA1

Etereticomis CesA1

E.calmabuluenss CesA

Effastigata CesA1

A.thaliana CesA 8
P.tichocapa CesA

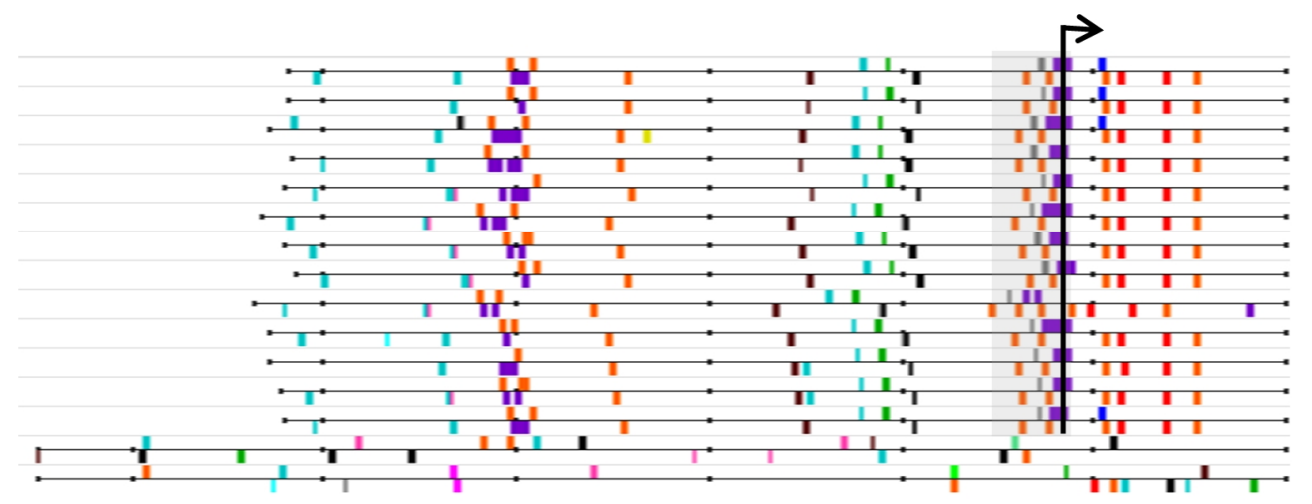

B E.globulus biscda CesA2 Eglobutus miderii CesA2
E.globutusgobutus CesA2 E.macarthuri CesA2

E.nitens CesA2

E.smithii CesA2

E.dunnii CesA2

E.saligna CesA2
E.urophyla CesA2

E.urophyla CesA2
E.grandis $\operatorname{Ces} A 2$

E.tereticomis CesA2

E.calmadulensis CesA2

E.fastigata CesA2

A.thaliana CesA 4

P.tichocapa CesAA

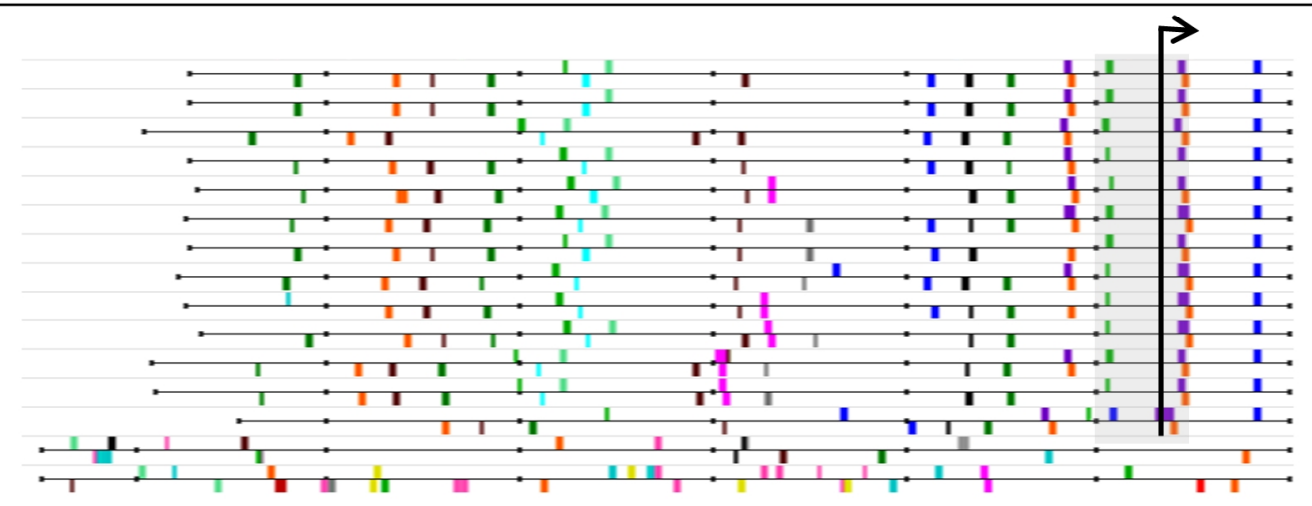

C E.globulus biscda CesA

t.globulus madern Cesas

E.gobuns goturis ceat

E.macarthuri $\operatorname{ces} A$

E.nitens CesA3

E.SmithirCesA3

E.dnin Cesa

E.salignacesA 3

Egrandis $\operatorname{ces} A 3$

E.grandis $\operatorname{Ces} A 3$
E tereticomis $\operatorname{CesA3} 3$

E.calmabuenss cesA3

E.calmaltuknss cesA

E.fastigata CesA3

P.trichocapa CesA7A

Ciselement key:

-CRPE6 CRPE25

- CRPE10

-

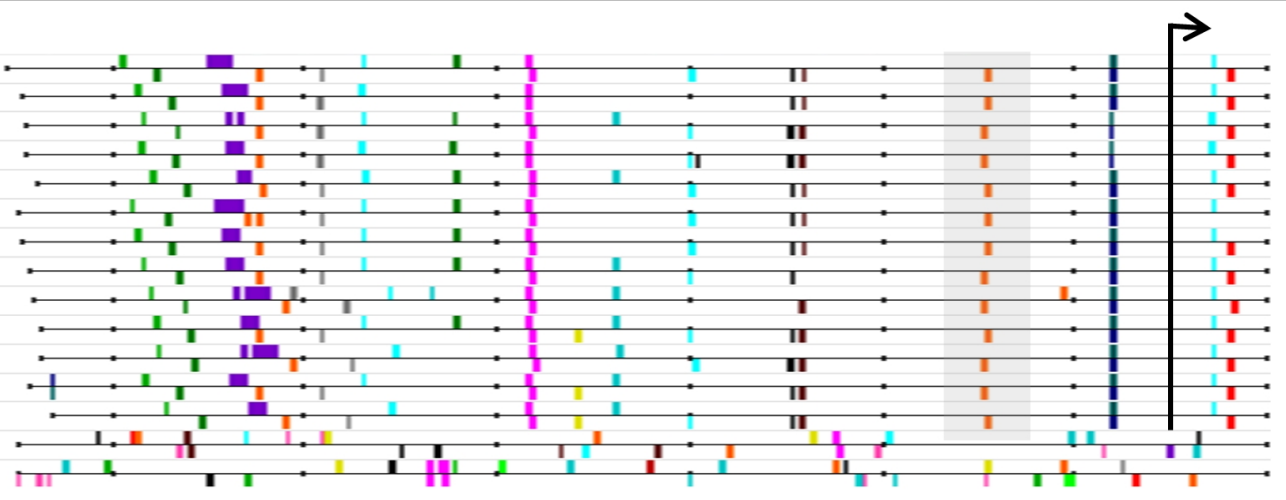

CRPE3

口CRPE26

CRPE12

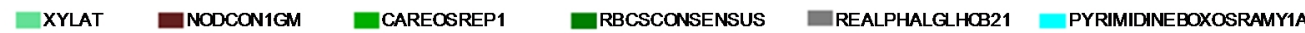
ETERE ETATABOX5 ECTRMCAMV35S ESEF4MOIIFGM7S DDRE2COREZMRAB17 
D

E.globulus biscda CesA4 Eglobulus maiderii CesA4 E.globulus gobutus CesA E.macarthurä Ces $A$

Enitens $\operatorname{ces} A 4$

E.smithii $\operatorname{Ces} A 4$

E.dunnii $\operatorname{Ces} A 4$

E.urophylla Ces $A A$

E.grandis CesA4

E.tereticomis CesA4

E.calmadulenss ces

E.fastgata CesA

A.thaliana CesA 3

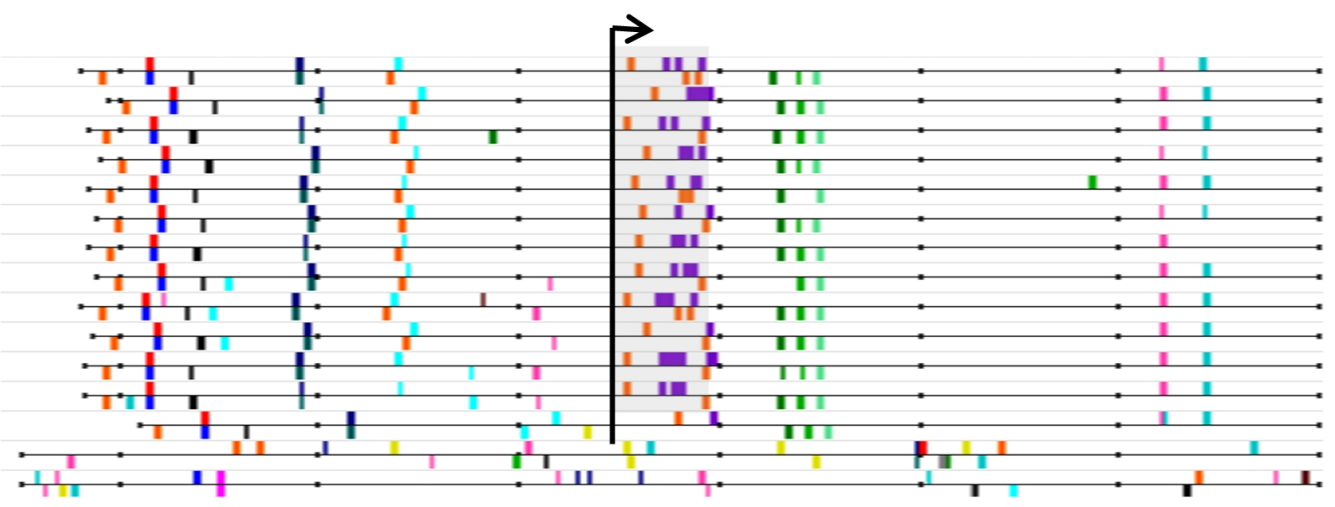

E Eglobulus tiscda CesA5 Eglobutus tiscda CesA5 E.globulus gohus $\mathrm{Ces} 5$ Emacarthurï CeAs

E.macarthurit Cess 15
E.nitens $\operatorname{Cos} A 5$

E.nitens CesAs

E.saligna Ces45

E. urophylla CesA5

E.grandis $\operatorname{Ces} A 5$

E.fastigata CesA5

A.thaliana CesA1

A.thaliana Cest 10

P.tichocapa CesA1-A

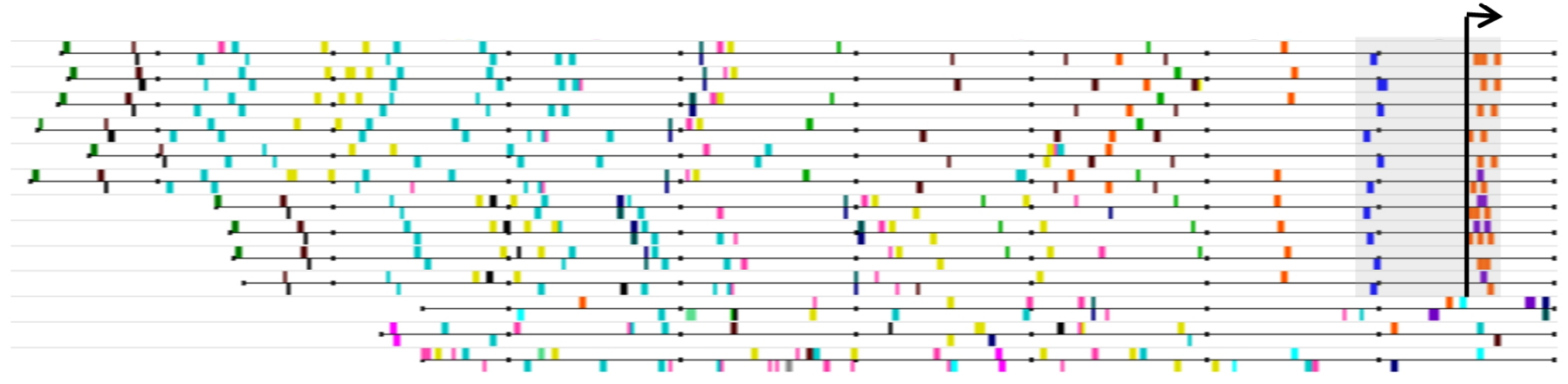

F E.globulus biscda CesA7

E.globulus maiderii CeSA7

Eglobulus gobutus CesA7

Emacarthuri CesA7

E.nitens $\operatorname{Ces} A 7$

E.smithiicesA7

E.dunnii CesA7

E.salignaCesA7

E.urophylla $\operatorname{Ces} A 7$

E.grandis $\operatorname{Ces} A 7$

E.tereticomis Ces47

E.calmabulenss CesA7

E.fastigata CesA7

A.thalianaCesA2

A.thalianaCesA6

A.thaliana CesA9

A.thaliana CesA5

P.trichocapa CesAG-A

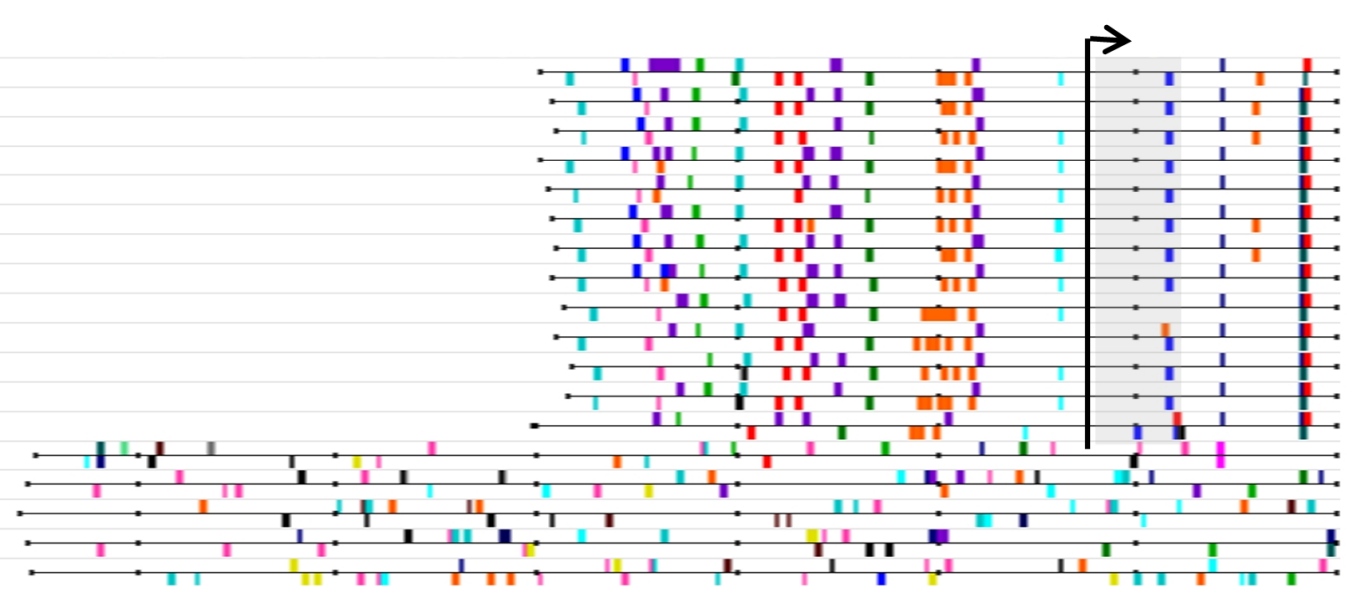

Cis-element key:

aCRPE 6 CRPE25

CRPE31 CRPE8

- CRPE10

- CRPE17

XYLAT

DNODCON1GM CAREOSREP1

ETERE

ETATABOX5

ERBCSCONSENSUS
EREF4MOIIFGM7S

EREALPHALGLHCB21 PYRIMIDINEBOXOSRAMY1A

CRPE26

TATABOA

\author{
Ectrmcamv35s
}


Figure 3. Occurrences of 21 putative cis-regulatory elements mapped in the promoters of six orthologous groups of CesA genes in 13 Eucalyptus species, Arabidopsis thaliana and Populus trichocarpa. The size of each promoter region and relative positions of mapped cis-elements in relation to the start codon (ATG) of each gene can be read from the ruler at the top. A colour key of cis-elements is given at the bottom of the image. The left hand margin of the figure shows the name and species of each promoter (grouped A-F). The horizontal black lines in each block represent the promoter sequences isolated for each species and the coloured squares show the position of the mapped cis-element occurrences. Squares above each line indicate cis-elements found in the sense orientation, while coloured squares below the lines indicate cis-element occurences found on the opposite strand. The predicted transcriptional start sites (TSSs) of the Eucalyptus promoters are indicated by the tailed arrow in each promoter set. The transparent grey blocks show putative cis-regulatory modules that coincide with the TSS positions. 


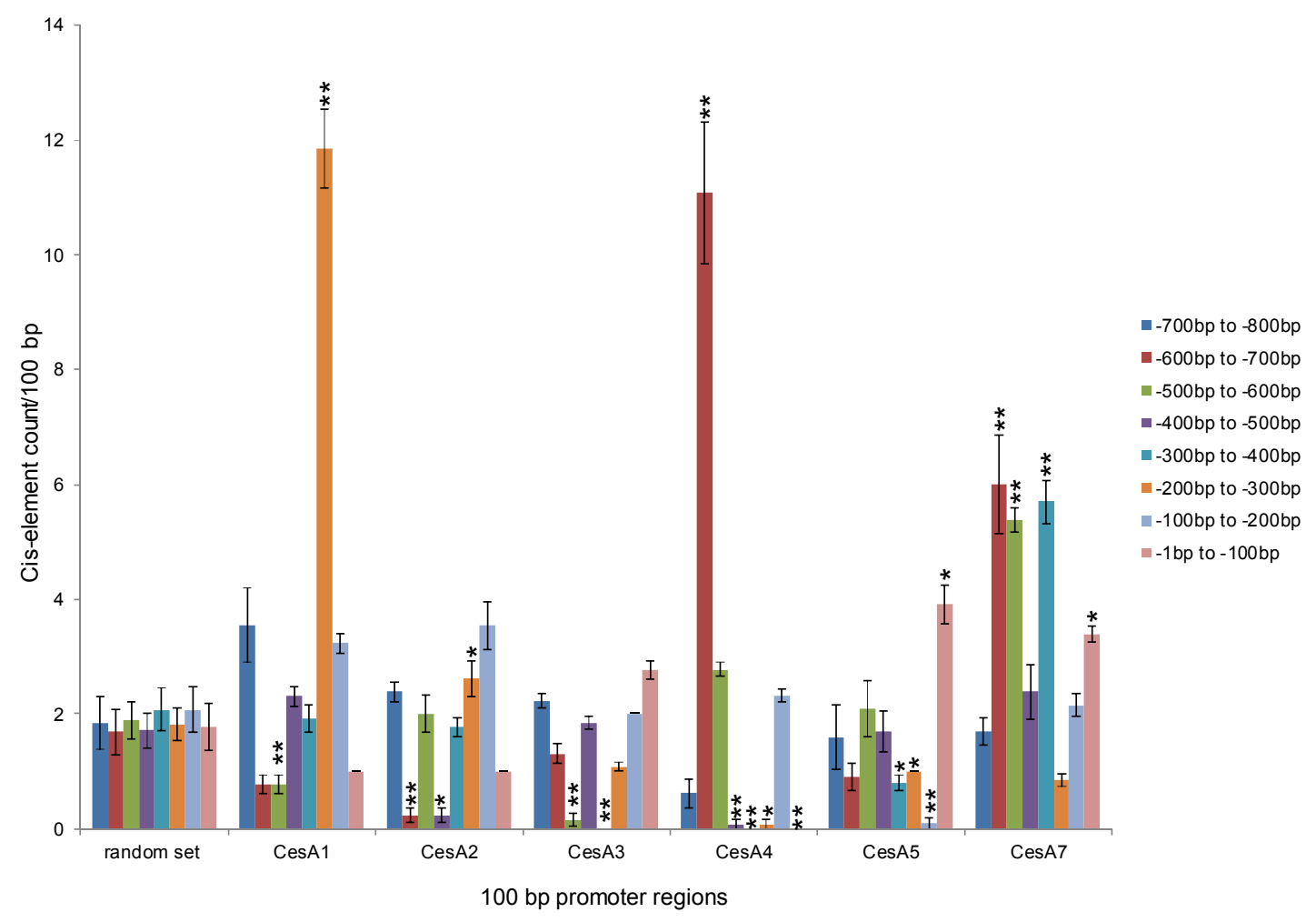

Figure 4. Frequency of cis-element occurrences along the length of the six CesA promoter regions averaged across the 13 Eucalyptus species in $100 \mathrm{bp}$ intervals, compared to a randomly generated sequence dataset. The random set reports the frequency of occurrences of 21 selected cis-elements in $100 \mathrm{bp}$ intervals along the length of a randomly generated dataset of non-coding upstream sequences ( $800 \mathrm{bp}$ of upstream from the ATG generated by the RSA-Tools random sequence generator, http://rsat.ulb.ac.be/rsat/). The frequency of ciselement occurrences in each of the CesA promoter sets (CesA1-5 and 7) are also indicated. The y-axis gives the number of cis-elements in each $100 \mathrm{bp}$ interval and the $\mathrm{x}$-axis represents the Ces $A$ promoter regions being analysed. The error bars show the standard error of the frequency measurement where $n=13$ (except for CesA5 where $n=10)$ and $*$ and $* *$ indicate significant differences from the random dataset $(p=0.01$ and 0.001 respectively; two tailed t-test assuming equal variance). 


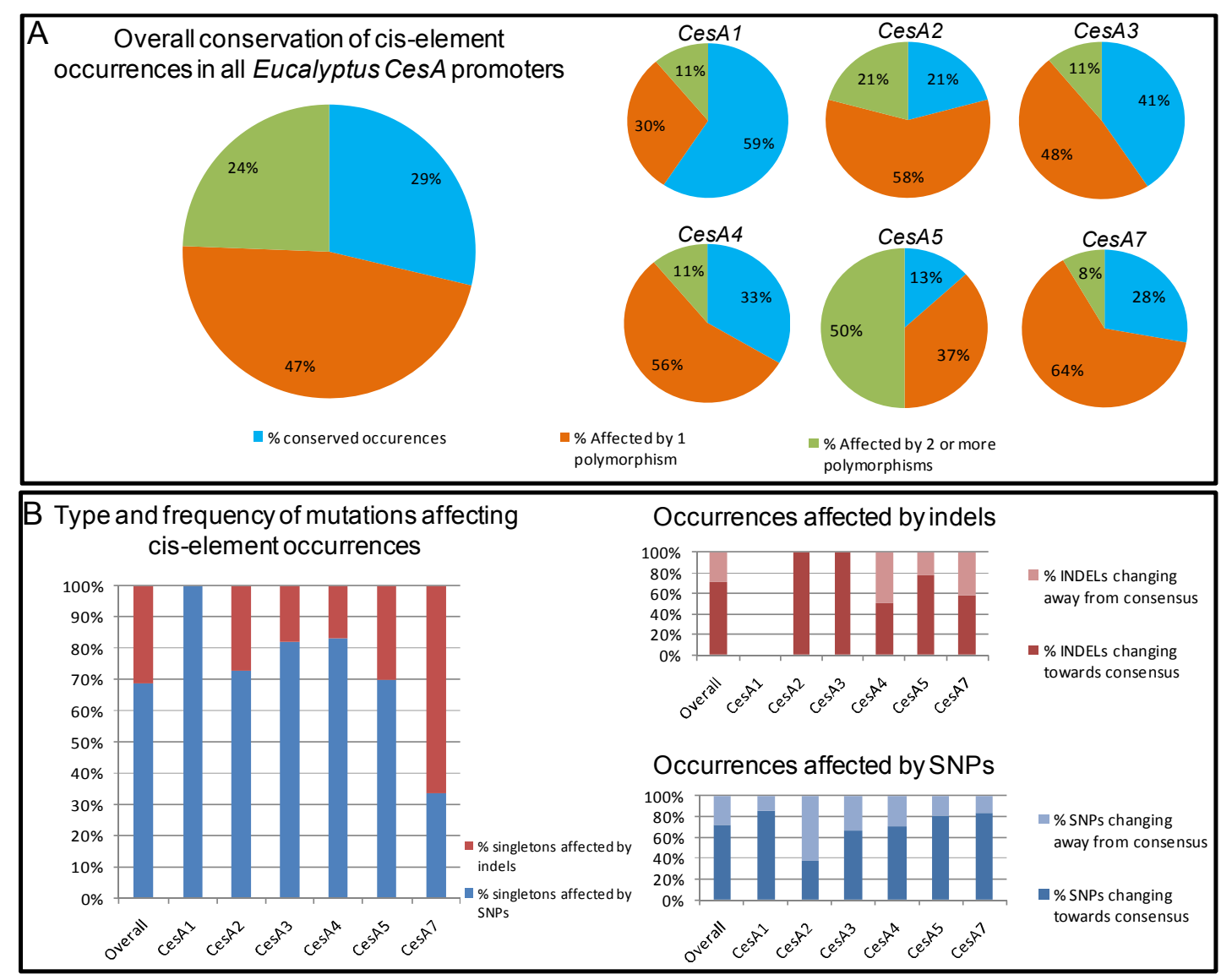

Figure 5. Evaluation of the types and frequency of polymorphisms observed within cis-element occurrences in the CesA promoter regions of 13 Eucalyptus tree species. A) Conservation of the cis-element consensus sequences across the Eucalyptus species. The cis-element occurrences were classified into three categories; conserved occurrences, which had no polymorphisms across all 13 species; occurrences affected by one polymorphism and occurrences affected by two or more polymorphisms (singleton changes were not counted as polymorphisms). The large pie chart on the left depicts the conservation in all promoters across all six genes, while the six smaller pie charts on the right show the cis-element sequence conservation within the promoter of each gene. B) The frequency of single nucleotide polymorphisms and indels in the promoter regions of 13 Eucalyptus CesA promoters. For this analysis, polymorphisms in cis-elements that only affect a single promoter of the 13 species (also refered to as singleton gains or losses) were investigated. The graph on the left represents the percentage of cis-element occurrences affected by SNPs and indels. The smaller red bar graph (top right corner) shows cis-element occurrences where an indel changed the sequence towards or away from the consensus sequence. Similarly the blue bar graph (bottom right) indicates cases where SNPs changed the ciselement sequence towards or away from the consensus sequence. 


\section{References}

Aspeborg H, Schrader J, Coutinho PM, Stam M, Kallas A, Djerbi S, Nilsson P, Denman S, Amini B, Sterky F, Master E, Sandberg G, Mellerowicz E, Sundberg B, Henrissat B, Teeri TT (2005) Carbohydrate-active enzymes involved in the secondary cell wall biogenesis in hybrid aspen. Plant Physiol 137: 983-997

Bernard V, Brunaud V, Lecharny A (2010) TC-motifs at the TATA-box expected position in plant genes: a novel class of motifs involved in the transcription regulation. BMC Genomics 11: 166

Blanchette M, Schwikowski B, Tompa M (2002) Algorithms for phylogenetic footprinting. J Comput Biol 9: 211-223

Blanchette M, Tompa M (2002) Discovery of regulatory elements by a computational method for phylogenetic footprinting. Genome Res 12: 739-748

Blanchette M, Tompa M (2003) FootPrinter: a program designed for phylogenetic footprinting. Nucl. Acids Res. 31: 3840-3842

Brooker MIH (2000) A new classification of the genus Eucalyptus L'Her. (Myrtaceae). Aust Syst Bot 13: 79-148

Burn JE, Hocart CH, Birch RJ, Cork AC, Williamson RE (2002) Functional analysis of the cellulose synthase genes CesA1, CesA2, and CesA3 in Arabidopsis. Plant Physiol 129: 797807

Burton RA, Shirley NJ, King BJ, Harvey AJ, Fincher GB (2004) The CesA gene family of barley. Quantitative analysis of transcripts reveals two groups of co-expressed genes. Plant Physiol 134: 224-236

Carmack CS, McCue L, Newberg L, Lawrence C (2007) PhyloScan: identification of transcription factor binding sites using cross-species evidence. Algorithm Mol Biol 2: 1

Creux NM, Ranik M, Berger DK, Myburg AA (2008) Comparative analysis of orthologous cellulose synthase promoters from Arabidopsis, Populus and Eucalyptus: evidence of conserved regulatory elements in angiosperms. New Phytol 179: 722-737

Crooks GE, Hon G, Chandonia JM, Brenner SE (2004) WebLogo: a sequence logo generator. Genome Res 14: 1188- 1190

Das M, Dai HK (2007) A survey of DNA motif finding algorithms. BMC Bioinformatics 8: S21

de Meaux J, Pop A, Mitchell-Olds T (2006) Cis-regulatory evolution of chalcone-synthase expression in the genus Arabidopsis. Genetics 174: 2181-2202

Demura T, Fukuda H (2007) Transcriptional regulation in wood formation. Trends Plant Sci 12: $64-70$

Desprez T, Juraniec M, Crowell EF, Jouy H, Pochylova Z, Parcy F, Hofte H, Gonneau M, Vernhettes S (2007) Organization of cellulose synthase complexes involved in primary cell wall synthesis in Arabidopsis thaliana. Proc Nat Acad Sci 104: 15572-15577

Ding J, Hu H, Li X (2012) Thousands of cis-regulatory sequence combinations are shared by Arabidopsis and poplar. Plant Physiol 158: 145-155

Eldridge K, Davidson J, Harwood C, Wyk GV (1994) Eucalypt domestication and breeding Oxford University Press, New york

Fang F, Blanchette M (2006) FootPrinter3: phylogenetic footprinting in partially alignable sequences. Nucleic Acids Res 34: W617-620

Farnham PJ (2009) Insights from genomic profiling of transcription factors. Nat Rev Genet 10: $605-616$

Freeling M, Subramaniam S (2009) Conserved noncoding sequences (CNSs) in higher plants. Curr Opin Plant Biol 12: 126-132 
Goicoechea M, Lacombe E, Legay S, Mihaljevic S, Rech P, Jauneau A, Lapierre C, Pollet B, Verhaegen D, Chaubet-Gigot N, Grima-Pettenati J (2005) EgMYB2, a new transcriptional activator from Eucalyptus xylem, regulates secondary cell wall formation and lignin biosynthesis. Plant J 43: 553-567

Gorshkova T, Brutch N, Chabbert B, Deyholos M, Hayashi T, Lev-Yadun S, Mellerowicz EJ, Morvan C, Neutelings G, Pilate G (2012) Plant fiber formation: state of the art, recent and expected progress, and open questions. CRC Cr Rev Plant Sci 31: 201-228

Grattapaglia D, Plomion C, Kirst M, Sederoff RR (2009) Genomics of growth traits in forest trees. Curr Opin Plant Biol 12: 148-156

Hall A (1999) BioEdit: a user-friendly biological sequence alignment editor and analysis program for Windows 95/98/NT. Nucleic Acids Symp Ser: 95-98

Hamann T, Osborne E, Youngs HL, Misson J, Nussaume L, Somerville C (2004) Global expression analysis of CESA and CSL genes in Arabidopsis. Cellulose 11: 279-286

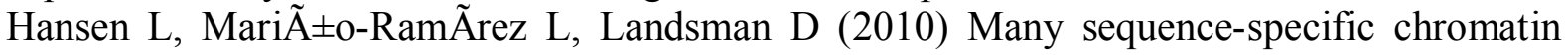
modifying protein-binding motifs show strong positional preferences for potential regulatory regions in the Saccharomyces cerevisiae genome. Nucleic Acids Res 38: 1772-1779

Hare EE, Peterson BK, Iyer VN, Meier R, Eisen MB (2008) Sepsid even-skipped enhancers are functionally conserved in Drosophila despite lack of sequence conservation. PLoS Genet 4: e1000106

Higo K, Ugawa Y, Iwamoto M, Korenaga T (1999) Plant cis-acting regulatory DNA elements (PLACE) database. Nucleic Acids Res 27: 297-300

Ho MCW, Johnsen H, Goetz SE, Schiller BJ, Bae E, Tran DA, Shur AS, Allen JM, Rau C, Bender W, Fisher WW, Celniker SE, Drewell RA (2009) Functional evolution of cisregulatory modules at a homeotic gene in Drosophila. PLoS Genet 5: e1000709

Hu R, Qi G, Kong Y, Kong D, Gao Q, Zhou G (2010) Comprehensive analysis of NAC domain transcription factor gene family in Populus trichocarpa. Bmc Plant Biology 10: 145

Karthikeyan AS, Ballachanda DN, Raghothama KG (2009) Promoter deletion analysis elucidates the role of cis elements and 5'UTR intron in spatiotemporal regulation of AtPht1;4 expression in Arabidopsis. Plant Physiol 136: 10-18

Keohavong P, Thilly WG (1989) Fidelity of DNA polymerases in DNA amplification. Proc Nat Acad Sci 86: 9253-9257

Kim HD, Shay T, O'Shea EK, Regev A (2009) Transcriptional regulatory circuits: predicting numbers from alphabets. Science 325: 429- 432

Ko J-H, Beers E, Han K-H (2006) Global comparative transcriptome analysis identifies gene network regulating secondary xylem development in Arabidopsis thaliana. Mol Genet Genom 276: 517-531

Koch MA, Weisshaar B, Kroymann J, Haubold B, Mitchell-Olds T (2001) Comparative genomics and regulatory evolution: conservation and function of the Chs and Apetala 3 promoters. Mol Biol Evol 18: 1882-1891

Kulheim C, Hui Yeoh S, Maintz J, Foley W, Moran G (2009) Comparative SNP diversity among four Eucalyptus species for genes from secondary metabolite biosynthetic pathways. BMC Genomics 10: 452

Kumar M, Thammannagowda S, Bulone V, Chiang V, Han K-H, Joshi CP, Mansfield SD, Mellerowicz E, Sundberg B, Teeri T, Ellis BE (2009) An update on the nomenclature for the cellulose synthase genes in Populus. Trends Plant Sci 14: 248-254

Legay S, Sivadon P, Blervacq A-S, Pavy N, Baghdady A, Tremblay L, Levasseur C, Ladouce N, Lapierre C, Séguin A, Hawkins S, Mackay J, Grima-Pettenati J (2010) EgMYB1, an R2R3 MYB transcription factor from Eucalyptus negatively regulates secondary cell wall formation in Arabidopsis and poplar. New Phytol 188: 774-786 
Ling LL, Keohavong P, Dias C, Thilly WG (1991) Optimization of the polymerase chain reaction with regard to fidelity: modified T7, Taq, and vent DNA polymerases. Genome Res 1: $63-69$

Livny J, Waldor MK (2009) Mining regulatory 5'UTRs from cDNA deep sequencing datasets. Nucleic Acids Res 38: 1504- 1514

Love J, Björklunda S, Vahala J, Hertzberg M, Kangasjärvib J, Sundberg B (2009) Ethylene is an endogenous stimulator of cell division in the cambial meristem of Populus. Proc Natl Acad Sci USA 106: 5984-5989

Lu S, Li L, Yi X, Joshi CP, Chiang VL (2008) Differential expression of three Eucalyptus secondary cell wall-related cellulose synthase genes in response to tension stress. J Exp Bot 59: 681-695

Maniatis T, Goodbourn S, Fischer JA (1987) Regulation of inducible and tissue-specific gene expression. Science 236: 1237-1245

McCarthy RL, Zhong R, Fowler S, Lyskowski D, Piyasena H, Carleton K, Spicer C, Ye Z-H (2010) The poplar MYB transcription factors, PtrMYB3 and PtrMYB20, are involved in the regulation of secondary wall biosynthesis. Plant Cell Physiol 51: 1084-1090

Mellerowicz EJ, Sundberg B (2008) Wood cell walls: biosynthesis, developmental dynamics and their implications for wood properties. Curr Opin Plant Biol 11: 293-300

Mizrachi E, Hefer C, Ranik M, Joubert F, Myburg A (2010) De novo assembled expressed gene catalog of a fast-growing Eucalyptus tree produced by Illumina mRNA-Seq. BMC Genomics 11: 681

Molina C, Grotewold E (2005) Genome wide analysis of Arabidopsis core promoters. BMC Genomics 6: 25

Mutwil M, Debolt S, Persson S (2008) Cellulose synthesis: a complex complex. Curr Opin Plant Biol 11: 252-257

Neale DB, Ingvarsson PK (2008) Population, quantitative and comparative genomics of adaptation in forest trees. Curr Opin Plant Biol 11(2):149-155.

Nei M (2007) The new mutation theory of phenotypic evolution. Proc Natl Acad Sci USA 104: $12235-12242$

Nei M, Li W (1979) Mathematical model for studying genetic variation in term of restriction endonucleases. Proc Natl Acad Sci (USA) 76: 5267-5273

Novaes E, Drost D, Farmerie W, Pappas G, Grattapaglia D, Sederoff R, Kirst M (2008) Highthroughput gene and SNP discovery in Eucalyptus grandis, an uncharacterized genome. BMC Genomics 9: 312

Pauli S, Rothnie HM, Chen G, He X, Hohn T (2004) The cauliflower mosaic virus 35S promoter extends into the transcribed region. J Virol 78: 12120-12128

Payn K, Dvorak W, Janse B, Myburg A (2008) Microsatellite diversity and genetic structure of the commercially important tropical tree species Eucalyptus urophylla, endemic to seven islands in eastern Indonesia. Tree Genet Genomes 4: 519-530

Piao SL, Fang JY, Ciais P, Peylin P, Huang Y, Sitch S, Wang T (2009) The carbon balance of terrestrial ecosystems in China. Nature 458: 1009-U1082

Popper ZA, Michel G, Herve C, Domozych DS, Willats WGT, Tuohy MG, Kloareg B, Stengel DB (2011) Evolution and diversity of plant cell walls: from algae to flowering plants. Annu Rev Plant Biol 62: 567-590

Pryor LD, Johnson LAS (1971) A classification of the Eucalypts. Australian National University, Canberra

Pyo H, Demura T, Fukuda H (2007) TERE; a novel cis-element responsible for a coordinated expression of genes related to programmed cell death and secondary wall formation during differentiation of tracheary elements. Plant J 51: 955-965 
Ragauskas AJ, Williams CK, Davison BH, Britovsek G, Cairney J, Eckert CA, Frederick WJ, Jr., Hallett JP, Leak DJ, Liotta CL, Mielenz JR, Murphy R, Templer R, Tschaplinski T (2006) The path forward for biofuels and biomaterials. Science 311: 484-489

Ranik M, Myburg AA (2006) Six new cellulose synthase genes from Eucalyptus are associated with primary and secondary cell wall biosynthesis. Tree Physiol 26: 545-556

Rathmann R, Szklo A, Schaeffer R (2010) Land use competition for production of food and liquid biofuels: An analysis of the arguments in the current debate. Renew Energ 35: 14-22

Regalbuto JR (2009) Cellulosic biofuels: Got gasoline? Science 325: 822- 824

Reineke AR, Bornberg-Bauer E, Gu J (2011) Evolutionary divergence and limits of conserved non-coding sequence detection in plant genomes. Nucleic Acids Res 39: 60296043

Roberts AW, Bushoven JT (2007) The cellulose synthase (CESA) gene superfamily of the moss Physcomitrella patens. Plant Mol Bio 63: 207 - 219

Rozas J, Sanchez-DelBarrio JC, Messeguer X, Rozas R (2003) DnaSP, DNA polymorphism analyses by the coalescent and other methods. Bioinformatics 19: 2496-2497

Samuga A, Joshi CP (2004) Differential expression patterns of two new primary cell wallrelated cellulose synthase cDNAs, PtrCesA6 and PtrCesA7 from aspen trees. Gene 334: 7382

Sarkar P, Bosneaga E, Auer M (2009) Plant cell walls throughout evolution: towards a molecular understanding of their design principles. J. Exp. Bot. 60: 3615-3635

Schneider TD, Stephens RM (1990) Sequence logos: a new way to display consensus sequences. Nucl. Acids Res. 18: 6097-6100

Shi R, Sun Y-H, Li Q, Heber S, Sederoff R, Chiang VL (2010) Towards a systems approach for lignin biosynthesis in Populus trichocarpa: transcript abundance and specificity of the monolignol biosynthetic genes. Plant Cell Physiol 51: 144-163

Steane DA, McKinnon GE, Vaillancourt RE, Potts BM (1999) ITS sequence data resolve higher level relationships among the eucalypts. Mol Phylogenet Evol 12: 215-223

Tamura K, Peterson D, Peterson N, Stecher G, Nei M, Kumar S (2011) MEGA5: Molecular evolutionary genetics analysis using maximum likelihood, evolutionary distance, and maximum parsimony methods. Mol Biol Evol 28: 2731-2739

Tanaka K, Murata K, Yamazaki M, Onosato K, Miyao A, Hirochika H (2003) Three distinct rice cellulose synthase catalytic subunit genes required for cellulose synthesis in the secondary wall. Plant Physiol 133: 73-83

Tanaka T, Koyanagi KO, Itoh T (2009) Highly diversified molecular evolution of downstream transcription start sites in rice and Arabidopsis. Plant Physiol 149: 1316 - 1324

Tanay A, Regev A, Shamir R (2005) Conservation and evolvability in regulatory networks: The evolution of ribosomal regulation in yeast. Proc Natl Acad Sci (USA) 102: 7203-7208

Taylor NG (2008) Cellulose biosynthesis and deposition in higher plants. New Phytol 178: 239-252

Taylor NG, Gardiner JC, Whiteman R, Turner SR (2004) Cellulose synthesis in the Arabidopsis secondary cell wall. Cellulose 11: 329-338

Taylor NG, Howells RM, Huttly AK, Vickers K, Turner SR (2003) Interactions among three distinct CESA proteins essential for cellulose synthesis. Proc Natl Acad Sci (USA) 100: 1450-1455

Than C, Ruths D, Nakhleh L (2008) PhyloNet: a software package for analyzing and reconstructing reticulate evolutionary relationships. BMC Bioinformatics 9: 322

Thomas-Chollier M, Sand O, Turatsinze J-V, Janky Rs, Defrance M, Vervisch E, Brohee S, van Helden J (2008) RSAT: regulatory sequence analysis tools. Nucleic Acids Res 36: W119- W127 
Thompson JD, Higgins DG, Gibson TJ (1994) CLUSTAL W: improving the sensitivity of progressive multiple sequence alignment through sequence weighting, position-specific gap penalties and weight matrix choice. Nucleic Acids Res 22: 4673-4680

Tjaden G, Edwards JW, Coruzzi GM (1995) Cis elements and trans-acting factors affecting regulation of a nonphotosynthetic light-regulated gene for chloroplast glutamine synthetase. Plant Physiol 108: 1109-1117

Tompa M, Li N, Bailey TL, Church GM, De Moor B, Eskin E, Favorov AV, Frith MC, Fu Y, Kent WJ, Makeev VJ, Mironov AA, Noble WS, Pavesi G, Pesole G, Regnier M, Simonis N, Sinha S, Thijs G, van Helden J, Vandenbogaert M, Weng Z, Workman C, Ye C, Zhu Z (2005) Assessing computational tools for the discovery of transcription factor binding sites. Nat Biotechnol 23: 137-144

Vandepoele K, Quimbaya M, Casneuf T, De Veylder L, Van de Peer Y (2009) Unraveling transcriptional control in Arabidopsis using cis-regulatory elements and coexpression networks. Plant Physiol 150: 535- 546

Watterson GA (1975) On the number of segregating sites in genetical models without recombination. Theor Popul Biol 7: 256-276

Wijaya E, Yiu S-M, Son NT, Kanagasabai R, Sung W-K (2008) MotifVoter: a novel ensemble method for fine-grained integration of generic motif finders. Bioinformatics 24: 2288-2295

Wu A-M, Hu J, Liu J-Y (2009) Functional analysis of a cotton cellulose synthase A4 gene promoter in transgenic tobacco plants. Plant Cell Rep 28: 1539-1548

Yamamoto YY, Ichida H, Abe T, Suzuki Y, Sugano S, Obokata J (2007) Differentiation of core promoter architecture between plants and mammals revealed by LDSS analysis. Nucleic Acids Res 35: 6219-6226

Yazaki J, Kishimoto N, Nagata Y, Ishikawa M, Fujii F, Hashimoto A, Shimbo K, Shimatani Z, Kojima K, Suzuki K, Yamamoto M, Honda S, Endo A, Yoshida Y, Sato Y, Takeuchi K, Toyoshima K, Miyamoto C, Wu J, Sasaki T, Sakata K, Yamamoto K, Iba K, Oda T, Otomo Y, Murakami K, Matsubara K, Kawai J, Carninci P, Hayashizaki Y, Kikuchi S (2003) Genomics approach to abscisic acid- and gibberellin-responsive genes in rice. DNA Res 10: 249-261

Yin Y, Huang J, Xu Y (2009) The cellulose synthase superfamily in fully sequenced plants and algae. BMC Plant Biol 9: 99

Zhao L, Lu L, Zhang L, Wang A, Wang N, Liang Z, Lu X, Tang K (2009) Molecular evolution of the E8 promoter in tomato and some of its relative wild species. J Biosci 34: 7183

Zhong R, Lee C, Ye Z-H (2010) Evolutionary conservation of the transcriptional network regulating secondary cell wall biosynthesis. Trends Plant Sci 15: 625-632

Zhong R, Lee C, Zhou J, McCarthy RL, Ye ZH (2008) A battery of transcription factors involved in the regulation of secondary cell wall biosynthesis in Arabidopsis. Plant Cell 20: 2763- 2782

\section{Data Archiving Statement}

All sequences used for analyses have been deposited on the GenBank database at NCBI (http://www.ncbi.nlm.nih.gov/) or have been previously published and are referenced as such. 
The Genbank accession numbers are listed in full in Online Resource 5 and in the Materials and Methods. The accession numbers are: JN573683 - JN573751 and JN573752 - JN573783. 